\title{
Structure and Bonding of Nanolayered Ternary Phosphides
}

\author{
Abdelkader Yakoubi $^{{ }^{*}}$, Hanane Mebtouche ${ }^{1}$, Mohamed Ameri ${ }^{2}$, Bachir Bouhafs ${ }^{1}$ \\ ${ }^{1}$ Modeling and Simulation in Materials Science Laboratory, Physics Department, University of Sidi Bel-Abbes, Sidi Bel-Abbes, Al- \\ geria; ${ }^{2}$ Département de Physique, Faculté des Sciences, Université Djillali Liabès, Sidi-Bel-Abbès, Algeria. \\ Email: *yakoubi_aek@yahoo.fr
}

Received April 2 ${ }^{\text {nd }}, 2011$; revised April 25 $5^{\text {th }}, 2011$; accepted May 25 $5^{\text {th }}, 2011$.

\begin{abstract}
We have studied the electronic structure and chemical bonding mechanism of nanolayered $M_{2} S b P$ with $M=T i, Z r$ and Hf using the full-relativistic of an all-electron full potential linearized augmented-plane-wave (FP-LAPW) method based on the density functional theory, within the local density approximation scheme for the exchange-correlation potential. Furthermore, we have to calculate the energy of formation for prove the existence of these compounds experimentally. Geometrical optimizations of the unit cell are in good agreement with the available theoretical and experimental data. The bulk modulus of $M_{2} \mathrm{SbP}$ conserved as Ti is replaced with $\mathrm{Zr}$, and increases by $8.7 \%$ as Ti is replaced with $\mathrm{Hf}$, which can be understood on the basis of the increased number of valence electrons filling the p-d hybridized bonding states. The bonding is of covalent-ionic nature with the presence of metallic character. Analyzing the bonding in the binary $M P$, it can be concluded that this character is essentially conserved in $M_{2} S b P$ ternaries.
\end{abstract}

Keywords: Ceramics, Ab-Initio Calculations, Electronic Structure, Crystal Structure, Equations-of-State

\section{Introduction}

$\mathrm{M}_{\mathrm{n}+1} \mathrm{AX}_{\mathrm{n}}(\mathrm{MAX})(\mathrm{n}=1$ to 3$)$ phases are a series of ceramics but with a combination of ductility, conductivity and machinability comparable to metals. $\mathrm{M}$ is an early transition metal, $\mathrm{A}$ is an A-group element (mostly IIIA and IVA) and $\mathrm{X}$ is either $\mathrm{C}$ or $\mathrm{N}$. These phases have hexagonal layered structures and belong to the space group $\mathrm{P}_{3} / \mathrm{mmc}$, where in $\mathrm{M}_{\mathrm{n}+1} \mathrm{X}_{\mathrm{n}}$ layers interleaved with pure layers of the A-group elements. The structures of the vast majority of these compounds were determined by Nowotny [1] and co-workers in the sixties.

The MAX phases are typical representatives of nanolaminated phases, and according to M. W. Barsoum et al. $[2,3]$, these phase characterized by high elastic moduli, are machinable [4], exhibit good damage tolerance [5], excellent thermal shock resistance [6], and good corrosion resistance [7], and they are good thermal and electrical conductors [4]. This unique combination of properties serves as motivation for fundamental as well as applied research. MAX phases are used as formers for healthcare products, hot pressing tools, and resistance heating elements $[8,9]$, and are suitable for many technological applications.
Extensive experimental and theoretical studies were reported on MAX phases because of their special mechanical, thermal and electrical properties. A. D. Bortolozo et al. [10] investigated $\mathrm{Ti}_{2} \mathrm{InC}$ by $\mathrm{x}$-ray diffraction, magnetic and resistivity measurements. This work sustains the idea of the existence of a new class of superconducting materials that crystallizes in the $\mathrm{Cr}_{2} \mathrm{AlC}$ prototype.

T. Scabarozi et al. [11] report on correlations between thermal expansion, elastic modulii, thermal transport, specific heat, and electrical transport measurements of materials within the MAX-phase family. Elastic modulus measurements are made using an ultrasonic time of flight technique. Thermal expansion measurements are made using high-temperature $\mathrm{x}$-ray diffractions.

Also, the electronic properties of these materials have been studied both theoretically and experimentally [12]. For MAX-phases in thin film form, the processing and physical properties have been recently reviewed.[13] Because the MAX-phases crystallize in a hexagonal structure the anisotropy of its conductivity is of great interest but it has been difficult to experimentally resolve this issue $[14,15]$.

This design criteria is not only limited to the carbides 
and nitrides ternary, but it can also be found in ternary phosphides crystallize in the same structure.

$\mathrm{M}_{2} \mathrm{SbP}(\mathrm{M}=\mathrm{Ti}, \mathrm{Zr}, \mathrm{Hf})$ compound belong to the MAX phases [2], the $\mathrm{Ti}_{2} \mathrm{SbP}, \mathrm{Zr}_{2} \mathrm{SbP}, \mathrm{Hf}_{2} \mathrm{SbP}$ compound have been less investigated compared to the other members of this family. Few experimental and theoretical works have been done to investigate their properties. Experimentally, H. Boller [15], synthesized this compound by power sintering at $800^{\circ} \mathrm{C}$. Theoretically, D. Music and co-workers [16] investigated the chemical bonding and elastic properties of this compound and the correlation between the electronic structure and elastic properties of nanolaminates ternary phosphides [17] using ab initio calculation.

In our paper, we present theoretical results of the bulk modulus and chemical bonding of $\mathrm{M}_{2} \mathrm{SbP}$ and see the effect of a different transition metals element of IVB group in the electronic properties. The aim of this work is to evaluate the chemical bonding and the bulk modulus of our compounds, as the number of valence electrons in third and fourth periods are increased to gain better insight into this technologically interesting class of materials.

\section{Methodology and Computational Details}

In this present work, the calculations of both crystal optimization and electronic structures were performed in the WIEN2K package [18]. The Kohn-Sham equations were solved by using the highly accurate all-electron full-potential linearized augmented plane-wave plus local orbitals (FP-L/APW + lo) method $[19,20]$ in the framework of density functional theory (DFT) with the exchange-correlation functional treated in the local density approximations (LDA) using the scheme of PerdewWang [21]. This method makes no shape approximation to the potential or the electron density. Within the FPLAPW method, the unit cell is divided into nonoverlapping muffin-tin (MT) spheres and an interstitial region. Inside the muffin-tin sphere of radius $\mathrm{R}_{\mathrm{MT}}$, the wave functions are expanded using radial functions (solution to the radial Schrödinger equation) times spherical harmonics up to $1_{\max }^{\mathrm{wf}}$, and the expansion of the potential inside the muffin-tin spheres is carried out up to $1_{\max }^{\text {Pot }}$. The parameter $\mathrm{R}_{\mathrm{MT}}^{\min } * \mathrm{~K}_{\max }=9.0 \quad\left(\mathrm{R}_{\mathrm{MT}}^{\min }\right.$ is the mallets muffin-tin spherical radius present in the system and $\mathrm{K}_{\max }$ is the truncation of the modulus of the reciprocal-lattice vector) is used to determine the number of plane waves needed for the expansion of the wave function in the interstitial region, while the parameter $G_{\max }$ is used to truncate the plane-wave expansion of the potential and density in the interstitial region. Here, the MT radii were set to $2.22,2.4$, and 2.7 a.u. for the $\mathrm{Ti}, \mathrm{Zr}$, and $\mathrm{Hf}$ atoms, respectively and 2.5, 1.9 a.u. for the $\mathrm{Sb}$ and $\mathrm{P}$ atoms respectively. Moreover, we let $\mathrm{R}_{\mathrm{MT}}^{\min } * \mathrm{~K}_{\max }=9.0$, $1_{\max }^{\mathrm{wf}}=10,1_{\max }^{\mathrm{Pot}}=4$, and $\mathrm{G}_{\max }=14$. The separate energy of -6.0 Ry was used between valence and core states. Thus, the Ti: $[\mathrm{Ar}] 3 \mathrm{~d}^{2} 4 \mathrm{~s}^{2}, \mathrm{Zr}$ : $[\mathrm{Kr}] 4 \mathrm{~d}^{2} 5 \mathrm{~s}^{2}$, and $\mathrm{Hf}$ : $[\mathrm{Xe}] 4 \mathrm{f}^{14} 5 \mathrm{~d}^{2} 6 \mathrm{~s}^{2}$, were treated as valence states, while $\mathrm{Sb}$ : $[\mathrm{Kr}] 4 \mathrm{~d}^{10} 5 \mathrm{~s}^{2} 5 \mathrm{p}^{3}$ and $\mathrm{P}$ : $[\mathrm{Ne}] 3 \mathrm{~s}^{2} 3 \mathrm{p}^{3}$ were acted as semicore states with other electrons as core states. The energy level of unoccupied states was calculated until 7.5Ry $\left(E_{\max }=7.5 \mathrm{Ryd}\right)$. Integrations in the first Brillouin zone (FBZ) have been performed using the Monkhorst-Pack method [22] with 111 special k points [23]. Self-consistency calculation of electronic structures is achieved when the total-energy variation from iteration to iteration converged to a 1 mRyd accuracy or better.

In the WIEN2K code, core states were treated at the fully relativistic approximation with including spin-orbit interaction [18] as the spin-orbit coupling (SOC) term in the Hamiltonian for the valence states, $\mathrm{H}^{\mathrm{SOC}}$, was treated as a perturbation in the second variationnel method, whereas the Dirac equation was solved for the core states. We compute lattice constants, bulk moduli and the optimized free internal parameters by fitting the total energy vs. volume curves to the equation of states [24].

The partial density of states and charge-density distributions are obtained using the relaxed structures at the equilibrium volumes. The input lattice parameters of the $\mathrm{M}_{2} \mathrm{SbP}$ studied are taken from Reference [17] and those of MP in the Hexagonal structure as well as TiSb alloy, which are used for the comparison purposes, can be found in References [34,35].

\section{Results and Discussion}

\subsection{Equilibrium, Formation of Energy and Cohesive Properties}

$\mathrm{M}_{2} \mathrm{SbP}(\mathrm{M}=\mathrm{Ti}, \mathrm{Zr}$, and $\mathrm{Hf})$ compounds crystallize in the Cr2AlC crystal structure, with space group $\mathrm{P} 63 / \mathrm{mmc}$ (\#194). Its unit cell contains two formula units, and the atoms occupy the Wyckoff positions 2 (a) $[(0,0,0),(0,0$, $1 / 2)]$ for $\mathrm{P}, 2$ (d) $[(1 / 3,2 / 3,3 / 4),(2 / 3,1 / 3,1 / 4)]$ for $\mathrm{Sb}$, and $4(\mathrm{f})[(1 / 3,2 / 3, \mathrm{z}),(2 / 3,1 / 3, z+1 / 2),(2 / 3,1 / 3,-\mathrm{z}),(1 / 3$, $2 / 3,-z+1 / 2)]$ for $M$, where $z$ is the internal free coordinate. The structure is thus defined by two lattice parameters, a and c, and the internal structural parameter, $\mathrm{z}$.

The phosphor $(\mathrm{P})$ atoms fill the octahedral locations between the M layers [16,17]. The repeating structure of the planes in the unit cell can be further defined by the $\mathrm{A}_{\mathrm{P}} \mathrm{C}_{\mathrm{M}} \mathrm{B}_{\mathrm{Sb}} \mathrm{C}_{\mathrm{M}} \mathrm{A}_{\mathrm{P}} \mathrm{B}_{\mathrm{M}} \mathrm{C}_{\mathrm{Sb}} \mathrm{B}_{\mathrm{M}}$ close-pack stacking along the $\mathrm{Z}$-axis [25-27]. The letters A, B, and C stand for the three distinct positions for atoms to occupy, in the closepacked $<0001>$ plane [29]. The subscripts denote the type of atom that sits at the site, e.g. $\mathrm{B}_{\mathrm{M}}$ means the metal atom $\mathrm{M}$ sits at a $\mathrm{B}$ site. The $\mathrm{Z}$-coordinate increases as we go from left to right. 
We have first chosen lattice parameters and internal parameters to start calculations. We then vary these parameters until reaching the minimum of energy. On the scale of meV, the energy bands near the energy gap depend critically on the structural parameters that are not determined by symmetry. We have therefore performed detailed structural optimizations of the unit cell geometries as a function of the external stress by minimizing the total energy. Our results of the calculated lattice constants a and c, bulk modulus and its pressure derivative, and the optimized free internal parameters are reported in Table 1. Good agreement between our calculations and experimental data of $\mathrm{H}$. Boller [15] and theoretical data of D. Music et al. [16,17] is obtained. Our calculations are slightly underestimated compared to the experimental values of as commonly observed in LDA calculations. The deviation from the experimental values of $\mathrm{c}$ and a for $\mathrm{Ti}_{2} \mathrm{SbP}$ was $1.03 \%$ and $1.65 \%$, respectively. For $\mathrm{Zr}_{2} \mathrm{SbP}$, the change from experimental values was $0.76 \%$ and $0.79 \%$, while for $\mathrm{Hf}_{2} \mathrm{SbP}$ it was $0.61 \%$ and $0.79 \%$, respectively [15]. Although the bulk moduli have not been experimentally measured, but a good agreement is observed with the other first principle data for the lattice parameters and the bulks moduli of $\mathrm{M}_{2} \mathrm{SbP}$ (they are treated the potential of exchange-correlation by the GGA) [16].

To study stabilities of relative phase for these phosphides hexagonal, we have calculated the energy of formation $\left(\mathrm{E}_{\text {form }}\right)$ per atom by using the following equation:

$$
\mathrm{E}_{\text {form }}^{\mathrm{M}_{2} \mathrm{SbP}}=\frac{\mathrm{E}_{\text {total }}^{\mathrm{M}_{2} \mathrm{SbP}}-4 \mathrm{E}_{\text {solid }}^{\mathrm{M}}-2 \mathrm{E}_{\text {solid }}^{\mathrm{Sb}}-2 \mathrm{E}_{\text {solid }}^{\mathrm{P}}}{8}
$$

where $\mathrm{M}$ designates a metal with $\mathrm{Ti}, \mathrm{Zr}$ and $\mathrm{Hf}$ crystallizing in the hexagonal structure (space group $\mathrm{P}_{3} / \mathrm{mmc}$, prototype $\mathrm{Mg}$ ) [29-31], $\mathrm{Sb}$ is a trigonal structure (space group $\mathrm{R} \overline{3} \mathrm{~m}$, prototype $\alpha \mathrm{As}$ ) [32], and $\mathrm{P}$ crystallize in the triclinic structure (space group $\mathrm{P} \overline{1}$ ) [33]. There are two atoms in the unit cell for every metal, the indication of the stability of these compounds with the following values according to these calculations of the energy of formation, for $\mathrm{Ti}_{2} \mathrm{SbP}, \mathrm{Zr}_{2} \mathrm{SbP}$ and $\mathrm{Hf}_{2} \mathrm{SbP}$ are -0.67 $\mathrm{eV} /$ atom, $-0.79 \mathrm{eV} /$ atom and $-0.74 \mathrm{eV} /$ atom respectively, these are listed in Table 2.

The cohesive energy is a measure of the strength of the forces that bind atoms together in the solid state and is

Table 1. The equilibrium lattice parameters (a, c and c/a), internal parameter (z), bulk modulus (B) and its pressure derivative (B') for $M_{2}$ SbP with $M=T i, Z r$, and Hf.

\begin{tabular}{|c|c|c|c|c|c|c|}
\hline Compounds & a $(\AA)$ & c $(\AA)$ & $\mathbf{c} / \mathbf{a}$ & $\mathbf{z}$ & B (GPa) & B' \\
\hline $\mathbf{T i}_{2} \mathbf{S b P}$ Present work & 3.58 & 12.42 & 3.47 & 0.099 & 134.6 & 4.11 \\
\hline $\operatorname{Exp}[15]$ & 3.64 & 12.55 & 3.45 & 0.100 & - & - \\
\hline $\operatorname{Ref}[16]$ & 3.65 & 12.63 & 3.46 & 0.100 & 115 & 4.25 \\
\hline $\mathbf{Z r}_{2}$ SbP Present work & 3.79 & 13.14 & 3.47 & 0.103 & 134.5 & 4.24 \\
\hline $\operatorname{Exp}[15]$ & 3.82 & 13.24 & 3.47 & 0.103 & - & - \\
\hline $\operatorname{Ref}[16]$ & 3.84 & 13.44 & 3.50 & 0.103 & 116 & 4.30 \\
\hline $\mathbf{H f}_{2} \mathbf{S b P}$ Present work & 3.76 & 12.96 & 3.45 & 0.102 & 144.4 & 4.13 \\
\hline $\operatorname{Exp}[15]$ & 3.78 & 13.04 & 3.45 & 0.102 & - & - \\
\hline Ref [16] & 3.81 & 13.21 & 3.47 & 0.102 & 125 & 4.19 \\
\hline
\end{tabular}

Table 2. The calculated values of the energy of formation $\left(E_{\text {form }}\right)$, bulk moduli $(B)$, cohesive energies $\left(E_{\text {coh }}\right)$ and the valence electron concentration (val-el) for $\mathrm{M}_{2} \mathrm{SbP}$.

\begin{tabular}{|c|c|c|c|}
\hline & $\mathrm{Ti}_{2} \mathrm{SbP}$ & $\mathrm{Zr}_{2} \mathrm{SbP}$ & $\mathrm{Hf}_{2} \mathrm{SbP}$ \\
\hline $\mathrm{E}_{\text {equilibre }}(\mathrm{eV})$ & -463670.52774 & -762143.63421 & -2012635.855 \\
\hline $\mathrm{E}_{\text {form }}(\mathrm{eV} / \mathrm{atom})$ & -0.69 & -0.79 & -0.74 \\
\hline $\mathrm{E}_{\mathrm{coh}}(\mathrm{eV} /$ atom $)$ & 12.75 & 13.25 & 15.44 \\
\hline $\mathrm{B}(\mathrm{GPa})$ & 134.6 & 134.5 & 144.4 \\
\hline Valence electron & 88 & 88 & 144 \\
\hline
\end{tabular}


descriptive in studying the phase stability. The cohesive energy $E_{\text {coh }}^{\mathrm{M}_{2} \mathrm{SbP}}$ of $\mathrm{M}_{2} \mathrm{SbP}$ is defined as the total energy of the constituent atoms minus the total energy of the compound where $\mathrm{E}_{\text {total }}^{\mathrm{M}_{2} \mathrm{Sb}}$ refers to the total energy of $\mathrm{M}_{2} \mathrm{SbP}$ in the equilibrium configuration and $\mathrm{E}_{\text {atom }}^{\mathrm{M}}$, $E_{\text {atom }}^{\mathrm{Sb}}$, and $E_{\text {atom }}^{\mathrm{P}}$ are the isolated atomic energies of the pure constituents.

$$
\mathrm{E}_{\mathrm{coh}}^{\mathrm{M}_{2} \mathrm{SbP}}=\left[2 \mathrm{E}_{\text {atom }}^{\mathrm{M}}-\mathrm{E}_{\text {atom }}^{\mathrm{Sb}}-\mathrm{E}_{\text {atom }}^{\mathrm{P}}\right]-\mathrm{E}_{\text {total }}^{\mathrm{M}_{2} \mathrm{SbP}}
$$

The isolated atomic energies are calculated using the same WIEN2K code by using the augmented plane-wave basis. The computed cohesive energies yield shown in (a) $\mathrm{Ti}_{2} \mathrm{SbP}$

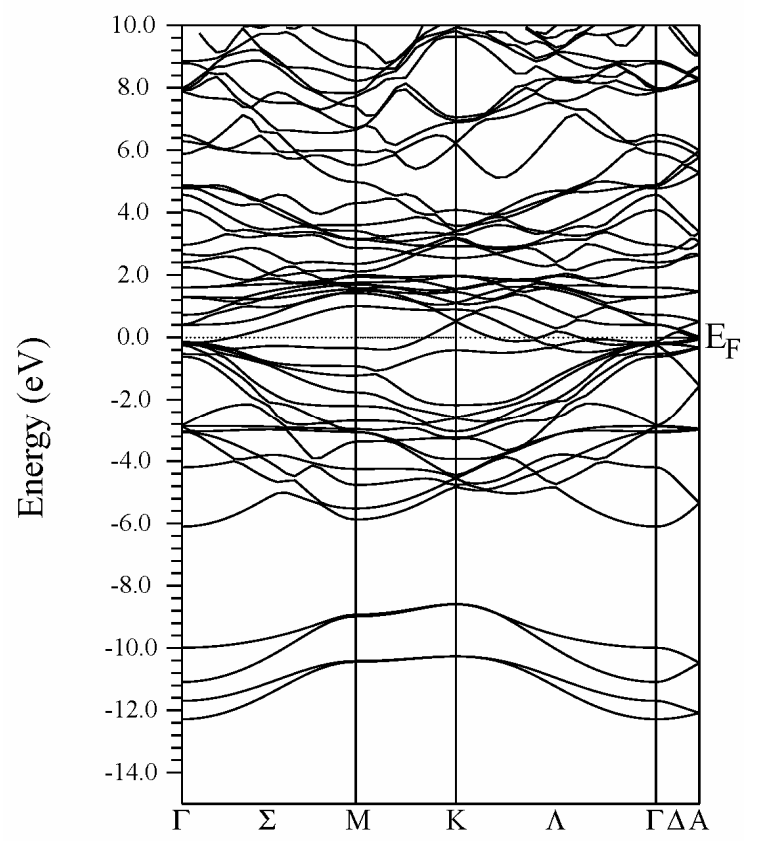

(b) $\mathrm{Zr}_{2} \mathrm{SbP}$

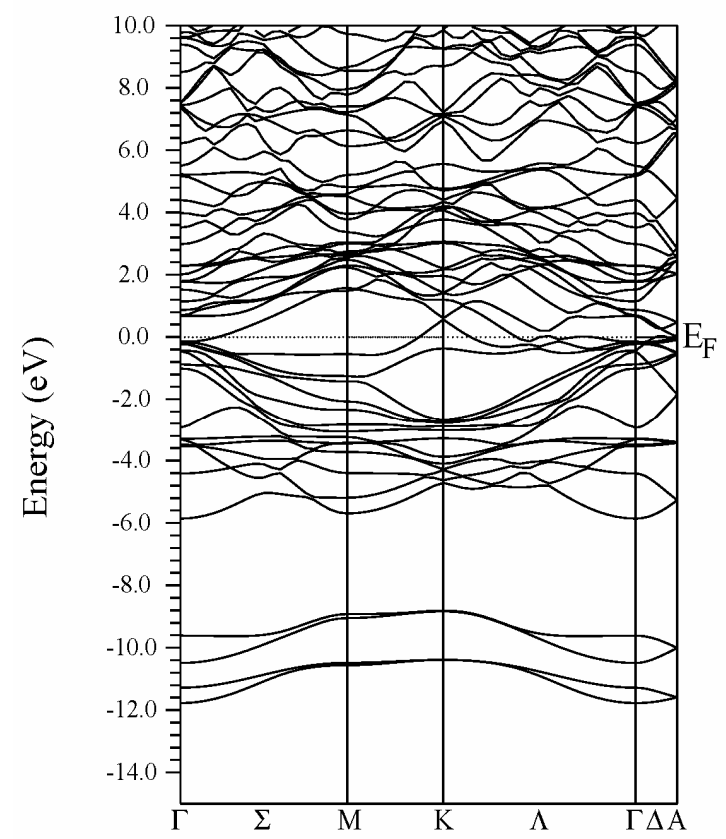

(c) $\mathrm{Hf}_{2} \mathrm{SbP}$

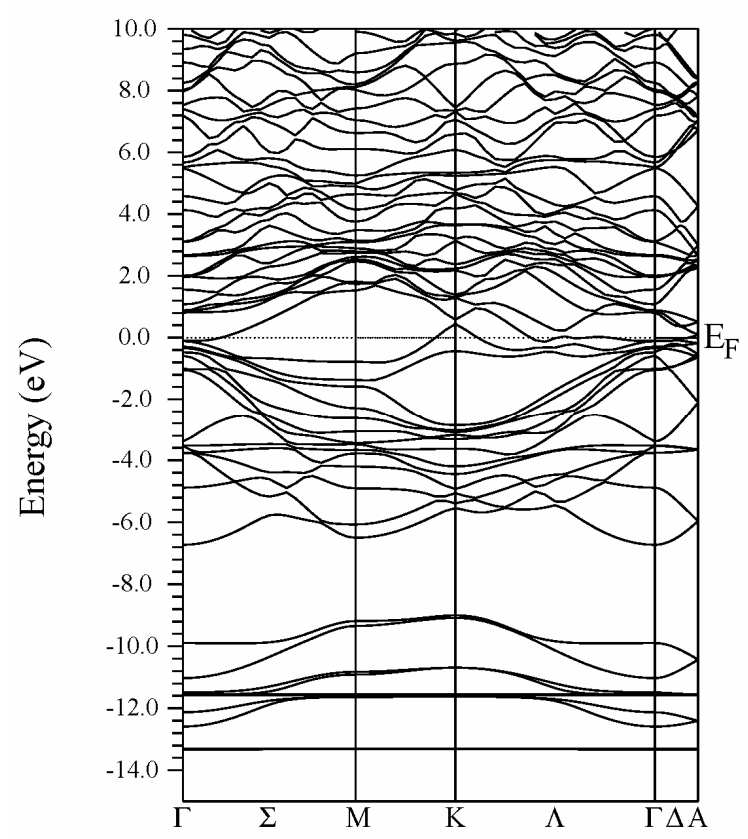

Figure 1. Full-relativistic LDA + SOC band structure of (a) $\mathrm{Ti}_{2} \mathrm{SbP}$, (b) $\mathrm{Zr}_{2} \mathrm{SbP}$ and (c) $\mathrm{Hf}_{2} \mathrm{SbP}$. 
Table 2. $12.75 \mathrm{eV} /$ atom for $\mathrm{Ti}_{2} \mathrm{SbP}, 13.25 \mathrm{eV} /$ atom for $\mathrm{Zr}_{2} \mathrm{SbP}$, and $15.44 \mathrm{eV} /$ atom for $\mathrm{Hf}_{2} \mathrm{SbP}$. It shows that the cohesive energies of the ternary first-column transitionmetal phosphides increase monotonously, as in the sequence $\mathrm{Ti}_{2} \mathrm{SbP}<\mathrm{Zr}_{2} \mathrm{SbP}<\mathrm{Hf}_{2} \mathrm{SbP}$.

The bulk modulus represents the resistance to volume change and is related to the overall atomic binding properties in a material. Therefore, we confirmed in the Table 2 , it is expected to change in the same trend of the cohesive energy, according to the transition-metal ion (the $\mathrm{M}$ element) and the valence electrons population of the $\mathrm{M}_{2} \mathrm{SbP}$.

\subsection{Band Structures and Density of States}

We calculated the electronic band structures using the full relativistic effects (including spin-orbit interaction) for $\mathrm{Ti}_{2} \mathrm{SbP}, \mathrm{Zr}_{2} \mathrm{SbP}$, and $\mathrm{Hf}_{2} \mathrm{SbP}$ are given in Figures 1(a), (b) and (c) respectively, at their equilibrium lattice constants at different high-symmetry points in the Brillouin zone.

The band structures also show strong anisotropic features with smaller energy dispersion along the c-axis. The valence and conduction bands overlap considerably and there is no band gap at the Fermi level. This finding confirms the metallicity of these materials. The electrical conductivity is anisotropic for this material, i.e. the electrical conductivity along the c-axis is much lower than that in the basal planes. The effect of the spin-orbit coupling (SOC) is clear in the $\mathrm{Hf}_{2} \mathrm{SbP}$ compound because the hafnium is a strongly correlated element.

The calculated total density of states (TDOS) using the $\mathrm{LDA}+\mathrm{SOC}$ for $\mathrm{M}_{2} \mathrm{SbP}$, where $\mathrm{M}=\mathrm{Ti}, \mathrm{Zr}$, and $\mathrm{Hf}$ are presented in Figure 2. It is apparent that these phases are alike, signifying similarity in chemical bonding. As shown in the figure, the Fermi level of $\mathrm{M}_{2} \mathrm{SbP}$ is located at a pseudogap between the bonding and nonbonding states. A similar pseudogap is also found in many other MAX phases [34,35]. Generally, a pseudogap correlates to the structure stability [36]. So it is believed that the presence of pseudogap in $\mathrm{M}_{2} \mathrm{SbP}$ contributed to its phase stability. At the Fermi level $\mathrm{E}_{\text {fermi, }}$, the DOS for $\mathrm{Ti}_{2} \mathrm{SbP}$, $\mathrm{Zr}_{2} \mathrm{SbP}$, and $\mathrm{Hf}_{2} \mathrm{SbP}$, were 2.12, 1.71 and 1.59 states per unit cell per $\mathrm{eV}$, respectively. Thus there is a small decreasing trend in the DOS at $\mathrm{E}_{\text {fermi }}$ with increasing atomic numbers of the transition metal (M).

To further elucidate the nature of chemical bonding in these compounds, we study the partial density of states (PDOS) of $\mathrm{Ti}_{2} \mathrm{SbP}$, a representative, given in Figure 3(a) Phosphorus does not contribute to the DOS at the Fermi level and therefore is not involved in the conduction properties. Ti d electrons are mainly contributing to the DOS at the Fermi level, and should be involved in the conduction properties. Sb electrons do not contribute significantly at the Fermi level. These results are consistent with previous reports on MAX phases [37]. It is evident that a covalent interaction occurs between the constituting elements due to the fact that states are degenerate with respect to both angular momentum and lattice site. P $3 p$ and Ti $3 d$ as well as $\mathrm{Sb} 4 \mathrm{p}$ and Ti $3 d$ states are hybridized. Also, due to the difference in electronegativity between the comprising elements, some ionic character can be expected. The bonding character may be described as a mixture of covalent-ionic and, due to the $\mathrm{d}$ resonance in the vicinity of the Fermi level, metallic. The pseudogap, common to all $\mathrm{M}_{2} \mathrm{SbP}$ phases studied (see Figure 2), is likely to split the bonding and antibonding orbitals. This behavior is consistent with previous reports on MAX phases [37-39].

Furthermore, it has been found for $\mathrm{Nb}_{3} \mathrm{SiC}_{2}$ [40] that the balanced crystal orbital overlap population analysis [41] is consistent with the PDOS analysis suggesting splitting in PDOS. However, there is also a difference with respect to the role of the A element. In the MAX phases [37,38] the A-M hybridization is weaker than the $\mathrm{Sb}-\mathrm{M}$ hybridization in the $\mathrm{M}_{2} \mathrm{SbP}$ phases. At the same time, the chemical bonding between $\mathrm{M}$ and $\mathrm{X}$ elements

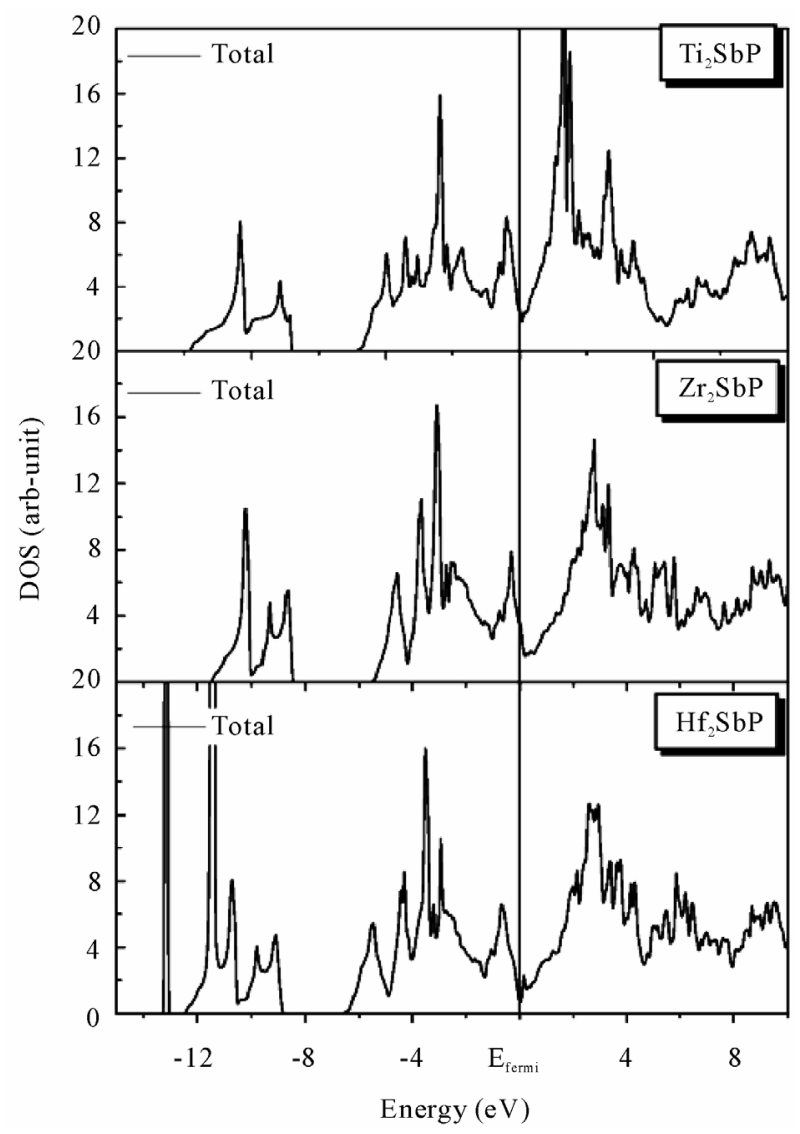

Figure 2. Full-relativistic total density of states (TDOS) for $\mathrm{M}_{2} \mathrm{SbP}$ with (M = Ti, Zr, Hf). 


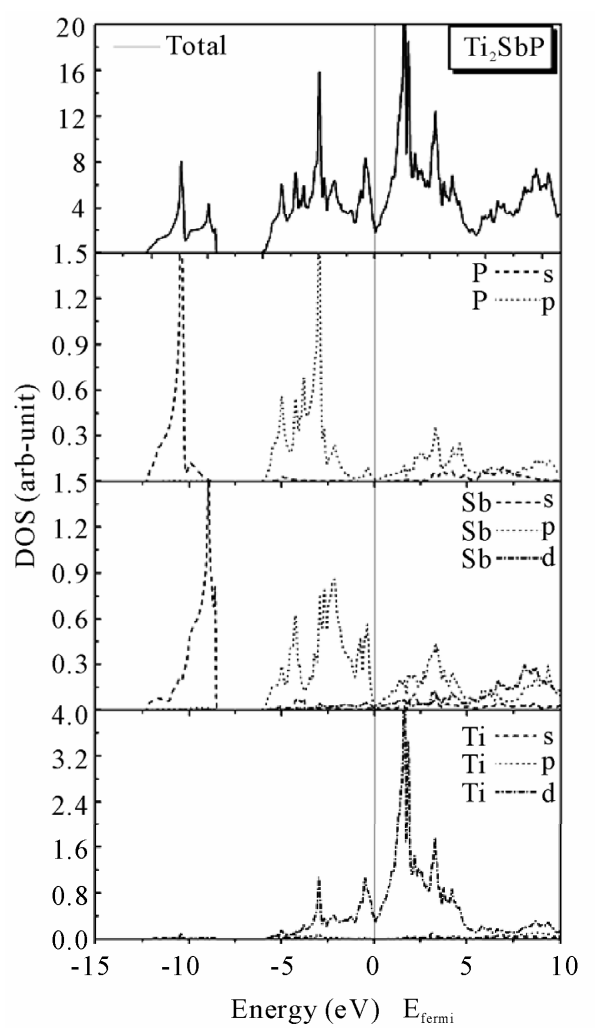

(a)

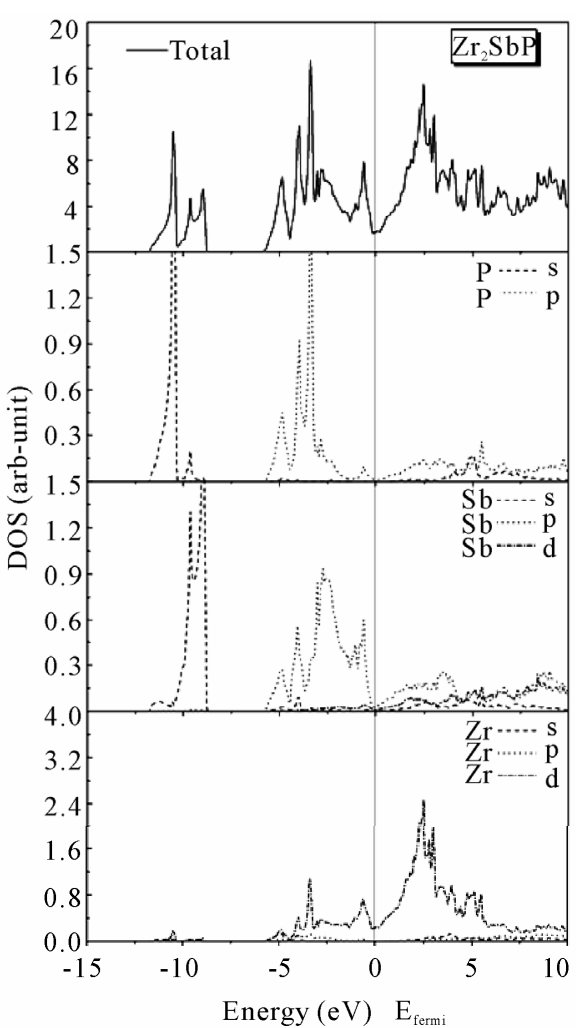

(b)

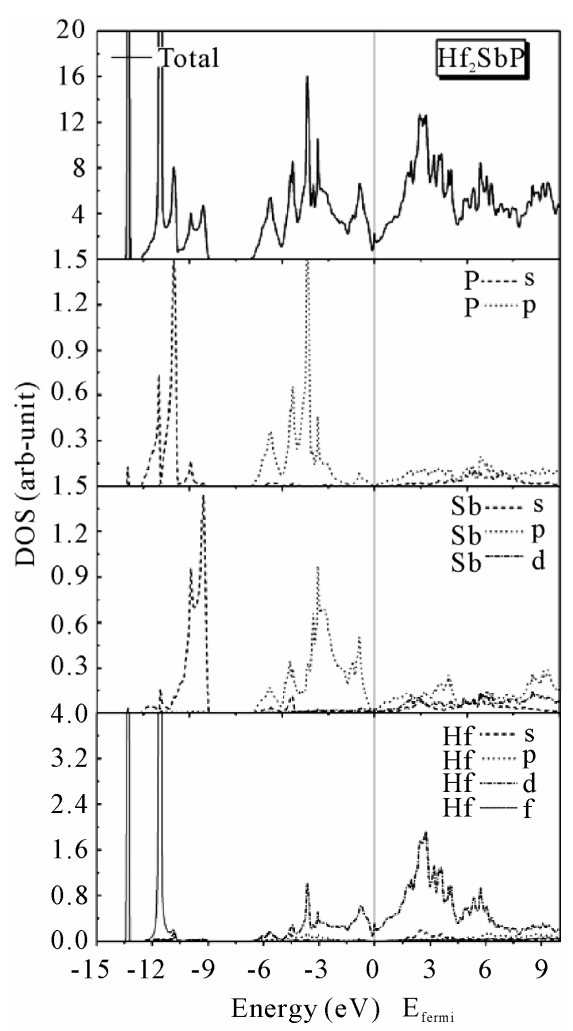

(c)

Figure 3. Full-relativistic partial density of states (PDOS) for $\mathrm{Ti}_{2} \mathrm{SbP}, \mathrm{Zr}_{2} \mathrm{SbP}$ and $\mathrm{Hf}_{2} \mathrm{SbP}$. 
in the MAX phases and between M and $\mathrm{P}$ in the here studied phosphides is rather similar (see Figures 3(a), (b), (c)).

\subsection{Charge Densities}

The high modulus of $\mathrm{Ti}_{2} \mathrm{SbP}$ can be explained based on bonding characters. To visualize the nature of the bond character and to explain the charge transfer and the bonding properties of the $\mathrm{Ti}_{2} \mathrm{SbP}, \mathrm{Zr}_{2} \mathrm{SbP}$ and $\mathrm{Hf}_{2} \mathrm{SbP}$ compounds, we have investigated the effect of the $\mathrm{M}$ states on the total charge densities (see Figure 4). It is known that MAX phases are usually stacks of 'hard' $\mathrm{M}-\mathrm{X}$ bond and "soft" M-A bond along c direction. For example, the Ti-C bond strength is much stronger than $\mathrm{Ti}-\mathrm{Al}$ bond in $\mathrm{Ti}_{2} \mathrm{AlC}$ [38]. However, for $\mathrm{Ti}_{2} \mathrm{SbP}$ (shown in Figure 4(a)), in addition to the Ti-P hybridization (covalent bonding), there is also a strong interaction between $\mathrm{Ti}$ and $\mathrm{Sb}$ atoms (metallic bonding). This means that the "soft" M-A bond is strengthened in $\mathrm{Ti}_{2} \mathrm{SbP}$, which is an extraordinary example in MAX phases studied so far. We believe that this strengthening effect contributed considerably to the increase in bulk modulus of $\mathrm{Ti}_{2} \mathrm{SbP}$. While the more electropositive nature of $\mathrm{Sb}$ confirms the ionic bonding between $\mathrm{Ti}$ and $\mathrm{Sb}$. Therefore, the chemical bonding in $\mathrm{Ti}_{2} \mathrm{SbP}$ is metallic-covalentionic in nature.

Figure 5 shows the charge-density contours in the $(11 \overline{20})$ plane for $\mathrm{Ti}_{2} \mathrm{SbP}$ Figure 5(a), as well as in the (1120) plane for TiP Figure 5(b), where the latter phase crystallizes in hexagonal structure with space group P63/mmc [42].

Analyzing the M-P bonding in TiP, it can be concluded that the bonding is characterized by covalent and ionic contributions and that this character is essentially conserved in the $\mathrm{M}_{2} \mathrm{SbP}$ ternaries. While the charge density distribution of TiP is similar to the one of $\mathrm{ZrP}$ and HfP, the charge distribution of the related ternaries shows extensive differences. The coupling between the MP layer and the $\mathrm{Sb}$ layer is weaker for $\mathrm{Ti}_{2} \mathrm{SbP}$ as compared to $\mathrm{Zr}_{2} \mathrm{SbP}$ and $\mathrm{Hf}_{2} \mathrm{SbP}$. In fact, the bonding between $\mathrm{Ti}$ and $\mathrm{Sb}$ in $\mathrm{Ti}_{2} \mathrm{SbP}$ is similar to the bonding in $\mathrm{TiSb}$ (space group $\mathrm{Cmcm}$ ) [43], as can be seen in Figure 5(c). Hence, the structure electronic data presented in Figure 2 can be understood based on the charge density data discussed here. These findings provide a pathway for tailoring the electronic properties of $\mathrm{M}_{2} \mathrm{SbP}$ by tuning the valence electron population. As the valence electron population of the transition metal $\mathrm{M}$ is increased, more charge is placed in the M-P bonds, which is due to an increase in the $\mathrm{P}$ p-M d hybridization as can be seen in Figure 2, where the partial density of states data are presented for $\mathrm{Ti}_{2} \mathrm{SbP}$ (Figure 3(a)), $\mathrm{Zr}_{2} \mathrm{SbP}$ (Figure 3(b)), and $\mathrm{Hf}_{2} \mathrm{SbP}$ (Figure 3(c)).

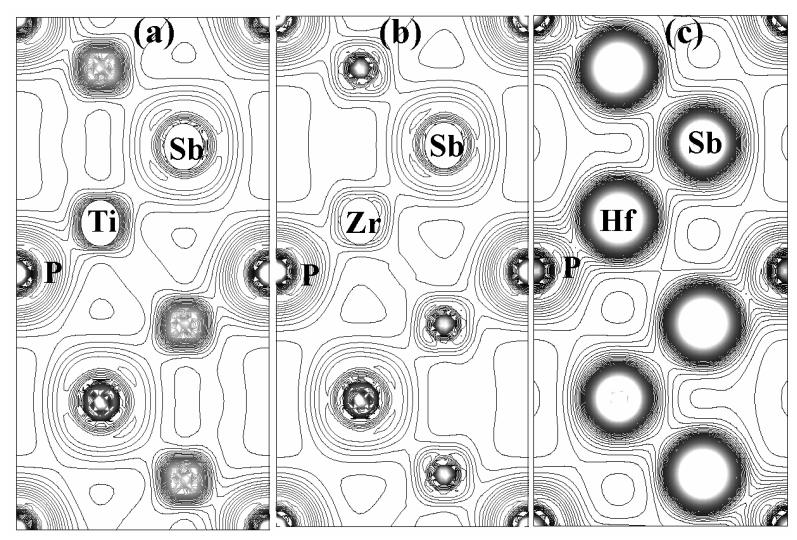

Figure 4. Electron density distribution of (a) $\mathrm{Ti}_{2} \mathrm{SbP}$, (b) $\mathrm{Zr}_{2} \mathrm{SbP}$, (c) $\mathrm{Hf}_{2} \mathrm{SbP}$, in the (1120) plane. The electron density distribution increases from 0.05 (white) to 15.0 (black) electron $/ \AA^{3}$ for $\mathrm{Ti}_{2} \mathrm{SbP}, \mathrm{Zr}_{2} \mathrm{SbP}$, and $\mathrm{Hf}_{2} \mathrm{SbP}$.

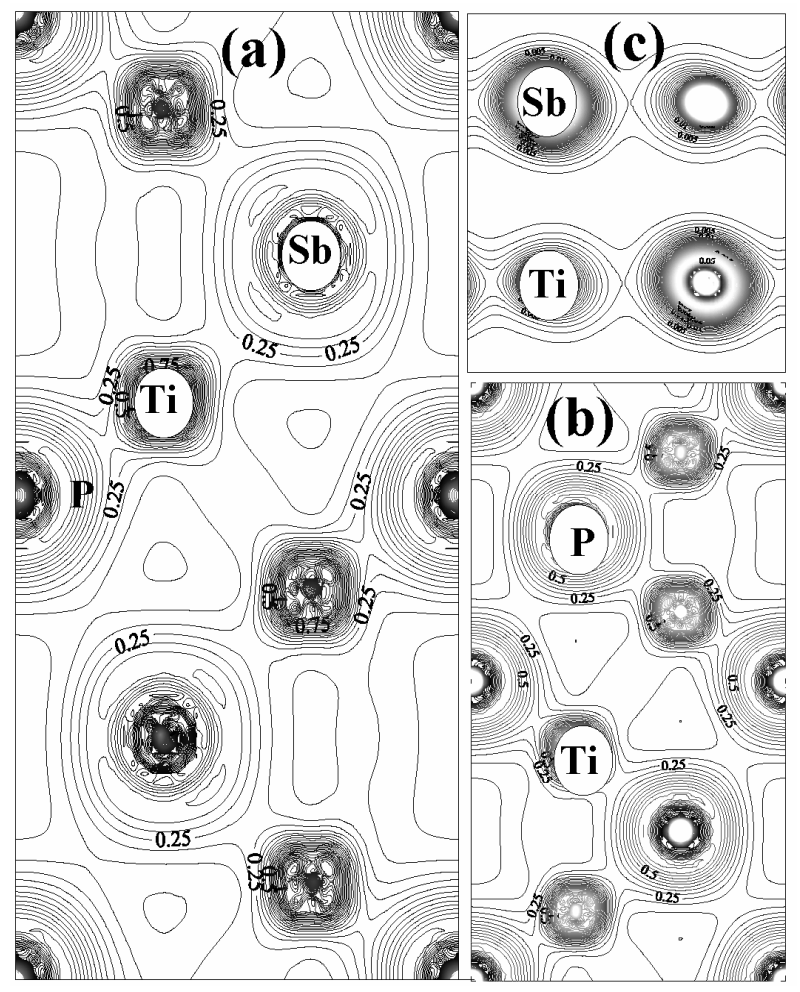

Figure 5. Contour plot of the total valence charge densities

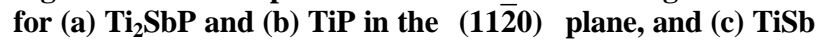
in the (100) plane.

\section{Conclusions}

In summary we have studied the electronic structure and chemical bonding of $\mathrm{M}_{2} \mathrm{SbP}$ compounds with $(\mathrm{M}=\mathrm{Ti}, \mathrm{Zr}$ and $\mathrm{Hf}$ ), by means of ab initio calculations using the full potential linearized augmented-plane-wave (FP-LAPW) method. The bulk modulus conserved as Ti is replaced with $\mathrm{Zr}$, and increases by $8.7 \%$ as $\mathrm{Ti}$ is replaced with $\mathrm{Hf}$. 
This can be understood since the substitution is associated with an increased valence electron concentration, resulting in band filling and an extensive increase in cohesion. To study stabilities of relative phase for these phosphides hexagonal, we have calculated the energy of formation $\left(E_{\text {form }}\right)$ per atom. The energy of formation indicates that these materials do form.

This work is important for basic understanding of structure and bonding of these phases and may encourage future experimental research.

\section{Acknowledgements}

One of us (B. B.) acknowledges the Abdus-Salam International Center for Theoretical Physics (Trieste-Italy).

\section{REFERENCES}

[1] H. Nowotny, "Strukturchemie Einiger Verbindungen der Ubergangsmetalle mit den Elementen C, Si, Ge, Sn," Progress in Solid State Chemistry, Vol. 5, 1971, pp. 27-70.

[2] M. W. Barsoum, "The $\mathrm{M}_{\mathrm{N}+1} \mathrm{AX}_{\mathrm{N}}$ Phases: A New Class of Solids: Thermodynamically Stable Nanolaminates," Progress in Solid State Chemistry, Vol. 28, No. 1-4, 2000, pp. 201-281. doi:10.1016/S0079-6786(00)00006-6

[3] M. W. Barsoum and T. El-Raghy, "The MAX Phases: Unique New Carbide and Nitride Materials," American Scientist, Vol. 89, No. 4, 2001, pp. 336-345.

[4] M. W. Barsoum and T. El-Raghy, "Synthesis and Characterization of a Remarkable Ceramic: $\mathrm{Ti}_{3} \mathrm{SiC}_{2}$," Journal of the American Ceramic Society, Vol. 79, No. 7, 1996, pp. 1953-1956. doi:10.1111/j.1151-2916.1996.tb08018.x

[5] M. W. Barsoum, T. El-Raghy and L. U. J. T. Ogbuji, "Oxidation of $\mathrm{Ti}_{3} \mathrm{SiC}_{2}$ in Air," Journal of the Electrochemical Society, Vol. 144, No. 7, 1997, pp. 2508-2516. doi:10.1149/1.1837846

[6] T. El-Raghy, et al., "Processing and Mechanical Properties of $\mathrm{Ti}_{3} \mathrm{SiC}_{2}$ : II. Effect of Grain Size and Deformation Temperature," Journal of the American Ceramic Society, Vol. 82, No. 10, 1999, pp. 2855-2860.

[7] Z. Sun, Y. Zhou, and M. Li, "Oxidation Behaviour of $\mathrm{Ti}_{3} \mathrm{SiC}_{2}$-Based Ceramic at $900^{\circ} \mathrm{C}-1300^{\circ} \mathrm{C}$ in Air," Corrosion Science, Vol. 43, No. 6, 2001, pp. 1095-1109. doi:10.1016/S0010-938X(00)00142-6

[8] "MAXTHAL Data Sheet," 3-One-2 LLC, Voorhees, New Jersey. http://www.3one2.com

[9] "Globar Bulk Ceramic Non-Inductive Resistors," Kanthal, an affiliate of Sandvic AB, Sandviken, Sweden. http://www.kanthal.com

[10] A. D. Bortolozo, O. H. Sant'Anna, C. A. M. dos Santos and A. J. S. Machado, "Superconductivity in the Hexagonal-Layered Nanolaminates $\mathrm{Ti}_{2} \mathrm{InC}$ Compound," Solid State Communications, Vol. 144, No. 10-11, 2007, pp. 419421. doi:10.1016/j.ssc.2007.09.028

[11] T. H. Scabarozi, S. Amini, P. Finkel, O. D. Leaffer, J. E. Spanier, M. W. Barsoum, M. Drulis, H. Drulis, W. M. Tambussi, J. D. Hettinger and S. E. Lofland, "Electrical,
Thermal, and Elastic Properties of the MAX-Phase Ti ${ }_{2} \mathrm{SC}$," Journal of Applied Physics, Vol. 104, No. 3, 2008, pp. 3502-3506. doi:10.1063/1.2959738

[12] M. Magnuson, M. Mattesini, S. Li, C. Höglund, M. Beckers, L. Hultman and O. Eriksson, "Bonding Mechanism in the Nitrides $\mathrm{Ti}_{2} \mathrm{AlN}$ and TiN: An Experimental and Theoretical Investigation," Physical Review B, Vol. 76, No. 19, 2007, pp. 5127-5135. doi:10.1103/PhysRevB.76.195127

[13] V. Mauchamp, G. Hug, M. Bugnet, T. Cabioc'h and M. Jaouen, "Anisotropy of $\mathrm{Ti}_{2} \mathrm{AlN}$ Dielectric Response Investigated by $a b$ Initio Calculations and Electron Energy-Loss Spectroscopy," Physical Review B, Vol. 81, No. 3, 2010, pp. 5109-5116. doi:10.1103/PhysRevB.81.035109

[14] N. Haddad, E. Garcia-Caurel, L. Hultman, M. W. Barsoum and G. Hug, "Dielectric Properties of $\mathrm{Ti}_{2} \mathrm{AlC}$ and $\mathrm{Ti}_{2} \mathrm{AlN}$ MAX Phases: The Conductivity Anisotropy," Journal of Applied Physics, Vol. 104, No. 2, 2008, pp. 3531-3540. doi:10.1063/1.2960340

[15] H. Boller, "Gemischte Pnictide Mit Geordnetem TiP-Typ (Ti ${ }_{2} \mathrm{SC}$-Typ)," Monatshefte für Chemie, Vol. 104, No. 1, 1973, pp. 166-171. doi:10.1007/BF00911157

[16] D. Music, Z. Sun, and J. M. Schneider, "Structure and Bonding of $\mathrm{M}_{2} \mathrm{SbP}(\mathrm{M}=\mathrm{Ti}, \mathrm{Zr}, \mathrm{Hf})$," Physical Review B, Vol. 71, No. 9, 2005, pp. 2102-2104. doi:10.1103/PhysRevB.71.092102

[17] D. Music and J. M. Schneider, "The Correlation between the Electronic Structure and Elastic Properties of Nanolaminates," Journal of the Minerals, Metals and Materials Society, Vol. 59, No. 7, 2007, pp. 60-64.

[18] P. Blaha, K. Schwarz, G. K. H. Madsen, D. Kvasnicka and J. Luitz, "WIEN2k: An Augmented Plane Wave + Local Orbitals Program for Calculating Crystal Properties," Technische Universität Wien, Vienna, 2001.

[19] G. K. H. Madsen, P. Blaha, K. Schwarz, E. Sjöstedt and L. Nordström, "Efficient Linearization of the Augmented Plane-Wave Method," Physical Review B, Vol. 64, No. 19, 2001, pp. 5134-5143. doi:10.1103/PhysRevB.64.195134

[20] K. Schwarz, P. Blaha and G. K. H. Madsen, "Electronic Structure Calculations of Solids Using the WIEN2k PackAge for Material Sciences," Computer Physics Communications, Vol. 147, No. 1-2, 2002, pp. 71-76. doi:10.1016/S0010-4655(02)00206-0

[21] J. P. Perdew and Y. Wang, "Accurate and Simple Analytic Representation of the Electron-Gas Correlation Energy," Physical Review B, Vol. 45, No. 23, 1992, pp. 13244-13249. doi:10.1103/PhysRevB.45.13244

[22] H. J. Monkhorst and J. D. Pack, "Special Points for Brillouin-Zone Integrations," Physical Review B, Vol. 13, No. 12, 1976, pp. 5188-5192. doi:10.1103/PhysRevB.13.5188

[23] P. E. Blöchl, O. Jepsen and O. K. Andersen, "Improved Tetrahedron Method for Brillouin-Zone Integrations," Physical Review B, Vol. 49, No. 23, 1994, pp. 16223-16233.

[24] F. D. Murnaghan, "The Compressibility of Media under 
Extreme Pressures," Proceedings of the National Academy of Sciences of the USA, Vol. 30, No. 9, 1944, pp. 244-247. doi:10.1073/pnas.30.9.244

[25] Naval Research Laboratory Center for Computational Materials Science, "Structures in a Hexagonal Space Group (\#168-\#194)," 2002.

http://cst-www.nrl.navy.mil/lattice/spcgrp/hexagonal.html \#sg194

[26] G. Hug, M. Jaouen and M. W. Barsoum, "X-Ray Absorption Spectroscopy, EELS, and Full-Potential Augmented Plane Wave Study of the Electronic Structure of $\mathrm{Ti}_{2} \mathrm{AlC}$, $\mathrm{Ti}_{2} \mathrm{AlN}, \mathrm{Nb}_{2} \mathrm{AlC}$, and $\left(\mathrm{Ti}_{0.5} \mathrm{Nb}_{0.5}\right)_{2} \mathrm{AlC}$," Physical Review $B$, Vol. 71, No. 2, 2005, pp. 4105-4116. doi:10.1103/PhysRevB.71.024105

[27] G. Hug and E. Fries, "Full-Potential Electronic Structure of $\mathrm{Ti}_{2} \mathrm{AlC}$ and $\mathrm{Ti}_{2} \mathrm{AlN}$," Physical Review B, Vol. 65, No. 11, 2002, pp. 3104-3107. doi:10.1103/PhysRevB.65.113104

[28] N. W. Ashcroft and N. D. Mermin, "Crystal Lattices," Solid State Physics, Chapter 4, Brooks/Cole, Belmont, 1976, pp. 64-83.

[29] R. R. Pawar and V. T. Deshpande, "The Anisotropy of the Thermal Expansion of $\alpha$-Titanium," Acta Crystallographica, Vol. A24, Part 2, 1968, pp. 316-317. doi:10.1107/S0567739468000525

[30] B. Olinger and J. C. Jamieson, "Zirconium: Phases and Compressibility to 120 Kilobars," High TemperaturesHigh Pressures, Vol. 5, No. 2, 1973, pp. 123-131.

[31] R. Russell, "On the Zr-Hf System," Journal of Applied Physics, Vol. 24, No. 2, 1952, pp. 232-233.

[32] D. Schiferl, "50-Kilobar Gasketed Diamond Anvil Cell for Single-Crystal X-Ray Diffractometer Use with the Crystal Structure of Sb up to 26 Kilobars as a Test Problem," Review of Scientific Instruments, Vol. 48, No. 1, 1977, pp. 24-30. doi:10.1063/1.1134861

[33] A. Simon, H. Borrmann and H. Craubner, "Crystal Structure of Ordered White Phosphorus ( $\beta$-P)," Phosphorus and Sulfur and the Related Elements, Vol. 30, No. 1-2, 1987, pp. 507-510. doi:10.1080/03086648708080631

[34] G. Hug and E. Fries, "Full-Potential Electronic Structure of $\mathrm{Ti}_{2} \mathrm{AlC}$ and $\mathrm{Ti}_{2} \mathrm{AlN}$," Physical Review B, Vol. 65, No.
11, 2002, pp. 3104-3107. doi:10.1103/PhysRevB.65.113104

[35] T. Liao, J. Y. Wang and Y. C. Zhou, "Superior Mechanical Properties of $\mathrm{Nb}_{2} \mathrm{AsC}$ to Those of Other Layered Ternary Carbides: A First-Principles Study," Journal of Physics: Condensed Matter, Vol. 18, No. 41, 2006, pp. L527L533. doi:10.1088/0953-8984/18/41/L04

[36] J. H. Xu and A. J. Freeman, "Band Filling and Structural Stability of Cubic Trialuminides: $\mathrm{YAl}_{3}, \mathrm{ZrAl}_{3}$, and $\mathrm{NbAl}_{3}$," Physical Review B, Vol. 40, No. 17, 1989, pp. 1192711930. doi:10.1103/PhysRevB.40.11927

[37] J. Wang and Y. Zhou, "Dependence of Elastic Stiffness on Electronic Band Structure of Nanolaminate $\mathrm{M}_{2} \mathrm{AlC}(\mathrm{M}$ $=\mathrm{Ti}, \mathrm{V}, \mathrm{Nb}$, and Cr) Ceramics," Physical Review B, Vol. 69, No. 21, 2004, pp. 4111-4120. doi:10.1103/PhysRevB.69.214111

[38] Z. Sun, D. Music, R. Ahuja, S. Li and J. M. Schneider, "Bonding and Classification of Nanolayered Ternary Carbides," Physical Review B, Vol. 70, No. 9, 2004, pp. 092102-092104. doi:10.1103/PhysRevB.70.092102

[39] Z. Sun, R. Ahuja, S. Li and J. M. Schneider, "Structure and Bulk Modulus of $\mathrm{M}_{2} \mathrm{AlC}(\mathrm{M}=\mathrm{Ti}, \mathrm{V}$, and $\mathrm{Cr})$," Applied Physics Letters, Vol. 83, No. 5, 2003, pp. 899-871. doi:10.1063/1.1599038

[40] A. Grechnev, S. Li, R. Ahuja, O. Eriksson, U. Jansson and $\mathrm{O}$. Wilhelmsson, "Layered Compound $\mathrm{Nb}_{3} \mathrm{SiC}_{2}$ Predicted from First-Principles Theory," Applied Physics Letters, Vol. 85, No. 15, 2004, pp. 3071-3073. doi:10.1063/1.1791734

[41] A. Grechnev, R. Ahuja and O. Eriksson, "Balanced Crystal Orbital Overlap Population-A Tool for Analysing Chemical Bonds in Solids," Journal of Physics: Condensed Matter, Vol. 15, No. 45, 2003, pp. 7751-7761. doi:10.1088/0953-8984/15/45/014

[42] H. F. Franzen, "Structure and Bonding in Metal-Rich Compounds: Pnictides, Chalcides and Halides," Progress in Solid State Chemistry, Vol. 12, No. 1, 1978, pp. 1-39. doi:10.1016/0079-6786(78)90002-X

[43] G. Melnyk, A. Leithe-Jasper, P. Rogl and R. Skolozdra, "The Antimony-Iron-Niobium (Sb-Fe-Nb) System," Journal of Phase Equilibria, Vol. 20, No. 2, 1999, pp. 113-118. 